\title{
OPTIMIZED MAINTENANCE DESIGN FOR MANUFACTURING PERFORMANCE IMPROVEMENT USING SIMULATION
}

\author{
Ahad Ali \\ Dept. of Mechanical Engineering \\ Lawrence Technological University \\ Southfield, MI 48975, USA
}

\author{
Xiaohui Chen \\ Research Institution of Industrial Engineering \\ Chongqing University \\ Chongqing, P.R. CHINA
}

Ziming Yang

Dept. of Mechanical Engineering

University of Michigan - Ann Arbor

Ann Arbor, MI 48109, USA

\author{
Jay Lee \\ Dept. of Mechanical Engineering \\ University of Cincinnati \\ Cincinnati, OH 45221, USA
}

\author{
Jun Ni \\ Dept. of Mechanical Engineering \\ University of Michigan - Ann Arbor \\ Ann Arbor, MI 48109, USA
}

\begin{abstract}
This research presents optimized maintenance design using simulation to analyze the capability of auto part manufacturing production system. The integration of simulation and optimization is used to identify critical stations, an optimal system design and maintenance scheduling schemes and evaluates their effects on the overall system performance. Most emphasis is focused on the impact on system by individual station reliability and the fluctuation of maintenance availability. The proposed simulation and optimization for maintenance design is validated through real-life application. This simulation modeling and optimization could help for manufacturing performance improvement.
\end{abstract}

\section{INTRODUCTION}

Researchers and practitioners have been using simulation and optimization to evaluate performance of manufacturing systems (Ólafsson and Kim 2002). However, a simple evaluation does not provide enough details for optimal decision-making. In some cases, simulation with optimization can provide better performance evaluations. There are many techniques and applications available for using simulation and optimization. Andradóttir (1998) and Azadivar (1999) provided reviews of simulation optimization techniques. Swicher et al. (2000) provided survey of simulation optimization techniques and procedures. Painter et al. (2006) presents an innovative methodology that combines simulation, data mining, and knowledge-based techniques to determine short and long-term impacts of candidate air- craft engine maintenance decisions for life-cycle cost and operational availability. April et al. (2001) provided realworld applications for simulation/ optimization. Hani et al. (2008) developed a simulation based optimization method to optimize the performances of a railway maintenance facility by choosing the best scheduling policy. Houshyar et al. (2003) studied the impact of preventive maintenance and investigated the possibility of executing the machinery builder's recommended preventive maintenance policy without adversely impacting the stipulated production quotas using ProModel simulation. Beyer (2006) presented simulation-based optimization of supply chain inventory and forecast policy using ISSOP. Krug et al. (2002) presented some basic ideas about optimization and discusses actual architectures of complex information systems, which include optimization systems or modules. In the complex systems, the large group of continuous parameter optimization methods are needed, while the discrete optimization methods are also used (Krug 1997 and ARENA/ISSOP Handbook 1997). This paper provides simulation and optimization of an auto manufacturing systems for performance evaluation specially for bottleneck identifications and maintenance policy selections.

Most current production systems have unsatisfactory overall availability due to excessive downtime caused by either quality related issues or machine/component failures. Current single station's mean-time-to-failure (MTTF) and mean-time-to-repair (MTTR) assessment does not reveal overall system performance and dynamic resourcing is not addressed in today's total productive maintenance (TPM) and manufacturing execution systems (MES). 
Scheduled downtime is to control when the system will be "down" in favor of production. Downtime will be more predictable if we could use preventive maintenance. As downtime becoming a controllable variable, system uncertainty will be lowered and production can be maximized through the reallocation of resources. The objective of this research is to use predictive information for better production/operation performance management, develop dynamic maintenance decision support system (DSS) to minimize maintenance investment and system downtime, and explore the feasibility of simulation tool with optimization for maintenance policy selection.

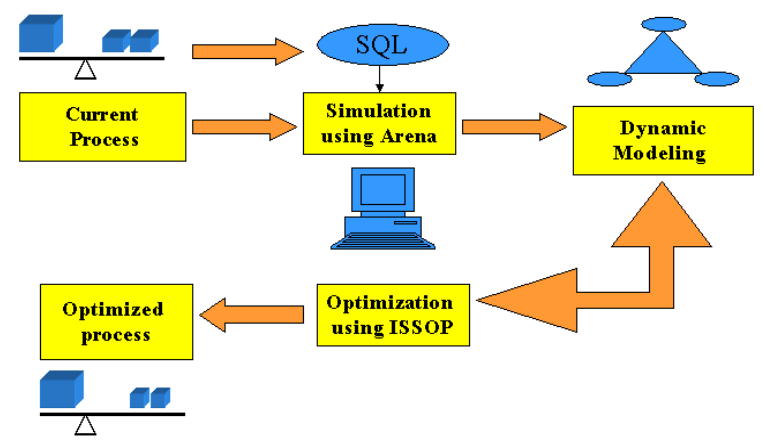

Figure 1: The embedded system process

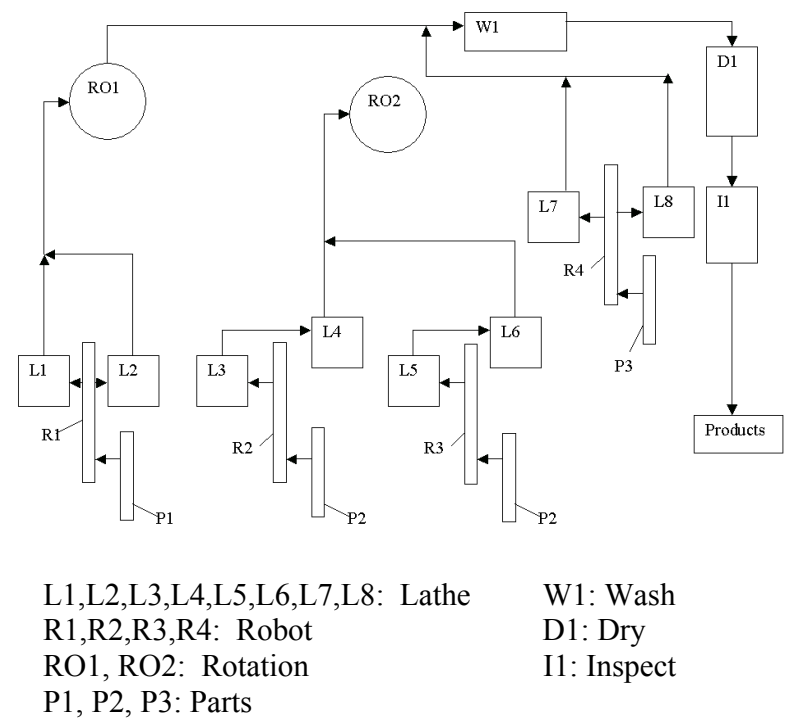

Figure 2: Overview of the production line

We chose the optimization software ISSOP (Intelligent System for Simulation and Optimization) and simulation software Arena to analyze the capability of auto part production line for Citation Custom Products. The embedded system process can be illustrated in the following Figure 1 . Based on the system understanding, we have developed a simulation model for existing system using Arena. After this dynamic model, we have developed model in
ISSOP to link discrete event modeling with optimization modules.

Three parts are produced separately in the three different work cells, and then they are assembled together as a final product. The overview of the production line is shown in Figure 2.

\section{SYSTEM INPUTS AND OUTPUTS}

Input variables are critical factors for successful simulation modeling. Station reliability and maintenance history are gathered from historical data. System configuration and station availability are observed and collected as necessary. General maintenance crew size and availability, spare stocks, stock size, and stocking schedule are used for simulation modeling. Time study is performed to obtain more recent operational data. Traditional stopwatch time study methods are used for collecting necessary data. Some of the data like station reliability and maintainability are analyzed from historical data, however station operation time and loading and unloading, etc. are collected by time study and analyzed with historical data as available.

Output variables of the modeling are considered as expected system performance measured in throughput, maintenance scheduling and restock policies. The availability of the station is based on the actual time and total time (availability = actual production time / total time). The covalence between availabilities is yet to be defined, based on the system configuration.

\section{SYSTEM LEVEL MODELING AND SIMULATION}

The model is used to identify critical stations and find the optimal system throughput using various scenarios. It helps to determine new maintenance scheduling schemes and evaluates their effects on the overall system performance. The test-bed production line being modeled contains 8 lathes, 3 dial stations, 1 washing station and 1 inspection station. The 8 lathes are arranged in 4 groups of 2, with each group supported by a robot. For the rest of the line, stations are connected with transfer belt, which serves as buffer at breakdown time. In the simulation model, there is no clear logical difference between a lathe and an inspection station, all of which takes certain amount of time to finish its task and all are prone to errors. Only the cycle time, MTTF and MTTR differs from station to station. We established a system simulation model to do "what if" analysis which is illustrated in Figure 3.

In order to give an authentic simulation of the actual production system, a pulling system is to be built. However, Arena does not have a definition of pulling system in its own component package. Therefore low-level logic programming is used to implement the pulling mechanism. For a station module, a buffer is attached at the entrance as 
the waiting queue for raw pieces. A signaling component is placed at the end of the station. Whenever a finished workpiece goes out of the station, the signaling component will inform the buffer in front to supply one raw piece into the station. If the buffer in front is empty, the signal is simply ignored. In such a manner, the control flow is then passed backwards from the end of the line to the very front. A processed piece will stay at last station until its destination station cleared and able to accept it. The influence of maintenance operation is modeled too. Instead of attaching maintenance resource directly to each station module, a centralized maintenance module is used. When a breakdown is triggered, similar to the bank teller system, a signal is sent to the listening component inside maintenance module. The event is rallied from there into the dispatching unit, which search for available maintenance resource, especially the maintenance personnel, and lock them during the period of simulated breakdown. When the required task is done, resources will be released back to resource pool. It marks the completion of maintenance activity.

In this implementation, a simple first-come-first-serve policy is modeled (Yang 2005). With the strength of low level logical programming provided by Arena, other policies can also be implemented. To simulation the breakdown, a set of unique entities is created at the beginning of the simulation. They are assigned with a breakdown flag that will be checked at each station. Whenever a station module receives such an entity, it will take another route other than the normal path to trigger the maintenance request and wait there until the request is finished. The entity is returned to the line upon request completion and be treated as ordinary entity afterwards. In close relation with the maintenance module, a simple but accurate and flexible system is modeled. Synchronize is done with current TPM system and the model is evaluated through the testbed at Citation Custom Products (Sherry 2002).

Multiple runs had been carried out on the simulation model with different system parameters. Most emphasis is focused on the impact on system by individual station reliability and the fluctuation of maintenance availability. The result obtained by confirmed a fact that the system performance, measured in the average throughput, is affected by multiple variables including station reliability, system layout, maintenance availability and maintenance policies. It also revealed that in situations where maintenance resource is not fully available, a delayed response to certain stations will be acceptable in order to have the minimum system impact and minimum maintenance investment. This implies a commonly recognized policy that maintenance resource should always be concentrated on critical stations (Yang et al. 2004). Another importance of this modeling lies in the fact that it provides a quantitative evaluation for maintenance operation from the production's viewpoint.
Optimization methods can be applied in find the best combination of input variable to achieve the highest throughput. One of the most eminent directions is to implement more maintenance policies into the model. First-comefirst-serve is the simplest policy that is definitely not optimized for production and maintenance. More profound policies should be implemented, with proper model modification. Given the maintenance information according to the history data, then the throughput of this system can be collected using the statistical analysis. Figure 4 is the results of balanced three work cells for the whole production line. From Figure 5, we can see that under different scenario the throughputs.

\section{OPTIMIZATION USING ISSOP}

Dynamic systems such as production lines, flexible manufacturing system, computer communication systems and traffic systems are discrete event systems. Most of these systems can be modeled in terms of discrete events whose occurrence causes the system to change from one state to another. In designing, analyzing and operating such complex systems, one is interested not only in performance evaluation but also in sensitivity analysis and optimization. Owing to the complex dynamics resulting from stochastic interactions of such discrete events over time, the performance analysis and optimization of DES can be difficult tasks. At the same time, since such systems are becoming widespread as a result of modern technological advances. It is important to have tools for analyzing and optimizing the parameters of these systems. At here, we choose Arena, which is product of Rockwell, and ISSOP, the product of Daulis company to do simulation and optimization of the dynamic systems, because of the software can transfer data between each other. The main user interface of ISSOP software is shown in Figure 6.

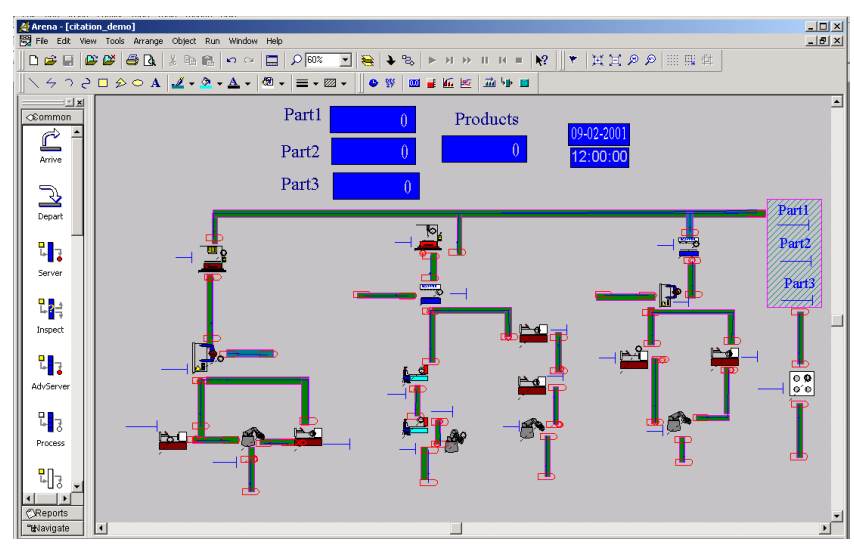

Figure 3: Animation of the production line 


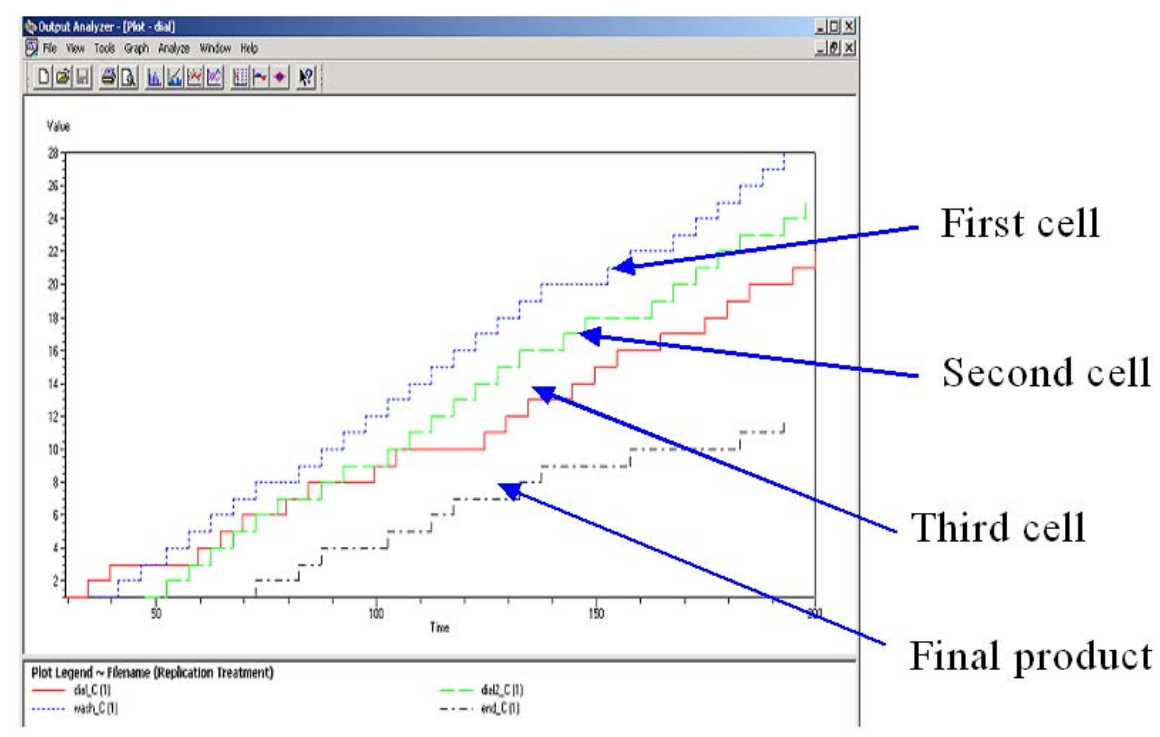

Figure 4: Simulation scenario - balanced production line

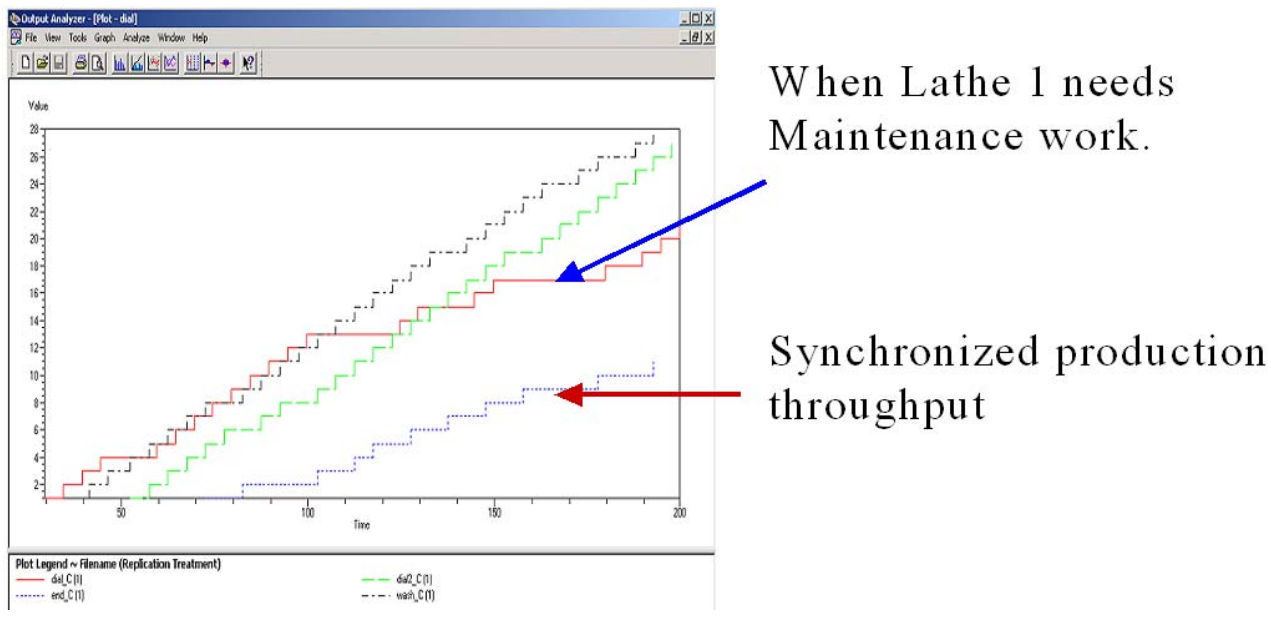

Figure 5: Simulation scenario - unbalanced production line

In terms of the requirements of the case study, there are 18,000 components (products) to be manufactured every week during two shifts. The amount of components is the result of 3,000 orders with different components types. The manufacturing is to be done with minimum costs and minimum flow time. We built a model assume that during each week there are one accident resulting in a production stop of two hours. Given the initial value of the model, we got the results after run the simulation model, such as the cost of system, process time and so on, showed in ISSOP (Figure 7).

From Figure 8 we can see that the objectives of this problem are considered cost minimization, order maximization and min process time. All of these we defined it in the ISSOP software. The constraints come form the simulation, such as capacity, etc. In order to get the optimal re- sults, this time we selected several different optimization algorithms to do optimization included in ISSOP software, for instance component wise enumeration, quasi gradient strategy, evolutionary strategy, Monte Carlo strategy, Genetic algorithm, etc. ISSOP and Arena work together to do the computation. Figure 9 and 10 are shown the setting of optimization.

As an example, the results can be displayed in a compromise table (Figure 11). The optimal results indicated that the cost was reduced, and the order was increased. The different optimization algorithm's results are presented. it is indicated that the optimal cost is 12 , when the orders of each shift are 8.1, the processing timing is $59 \mathrm{~min}$, and the number of the operator is 9. Compared with the initial result, through a certain optimization search the cost was re- 
duced 7.69 percentage. Base on this optimization results, the optimal maintenance design is developed and validated.

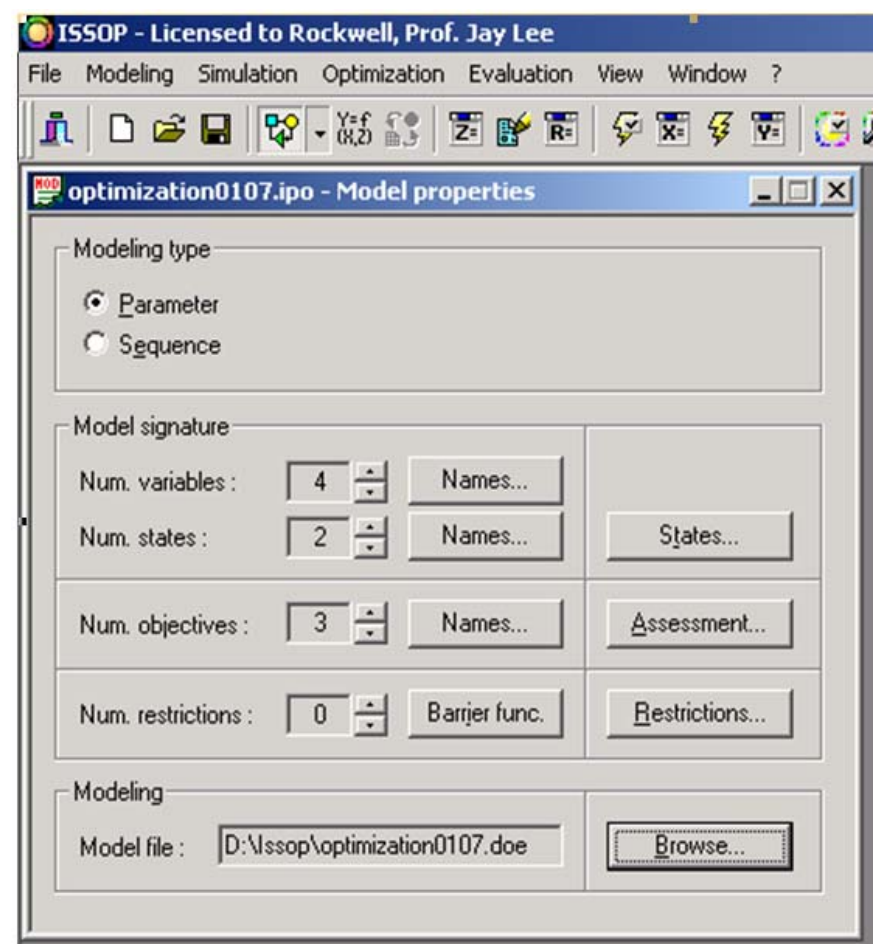

Figure 6: Optimization model properties using ISSOP

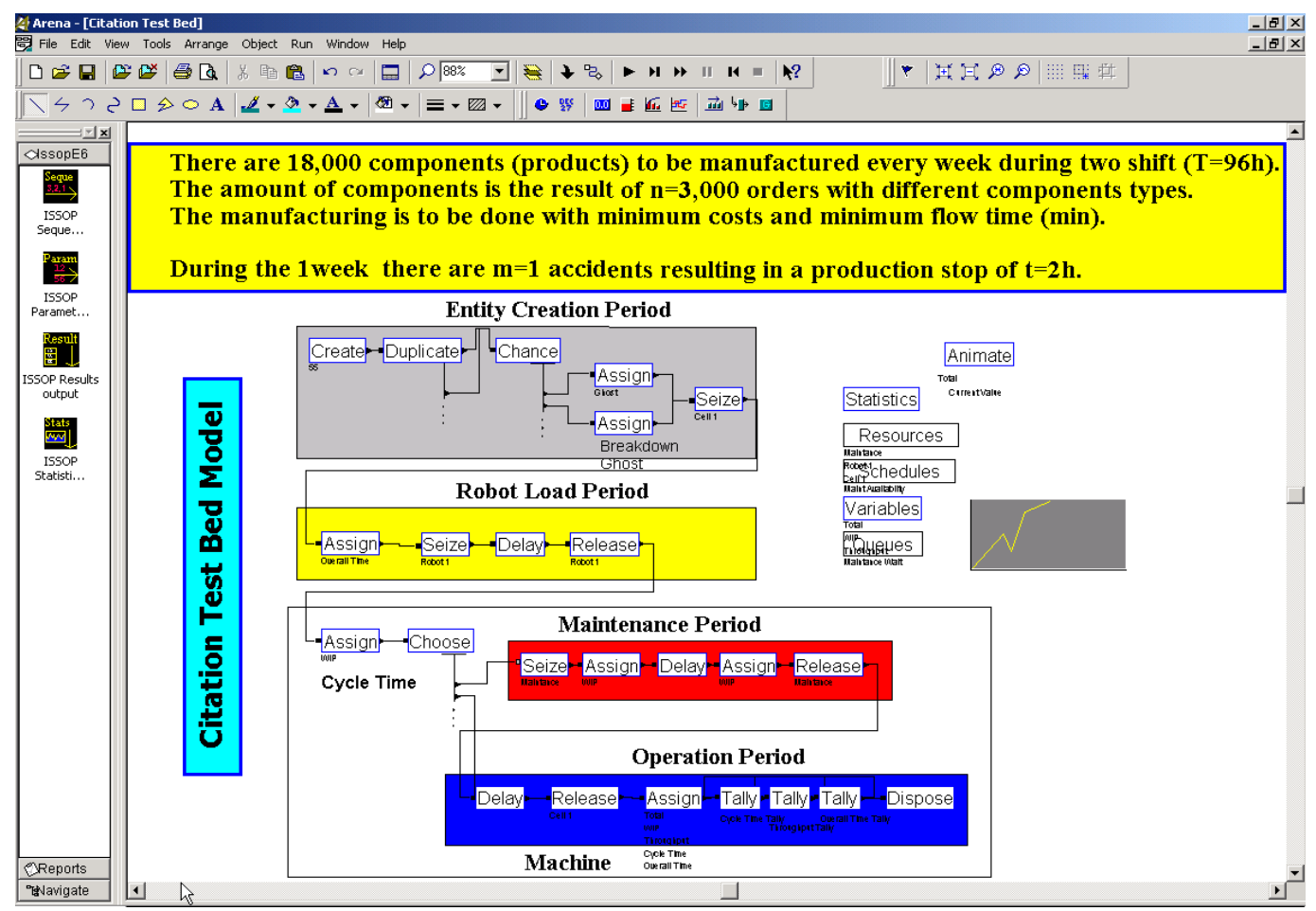

Figure 7: Optimization model in Arena 


\section{Ali, Chen, Yang, Lee, and Ni}

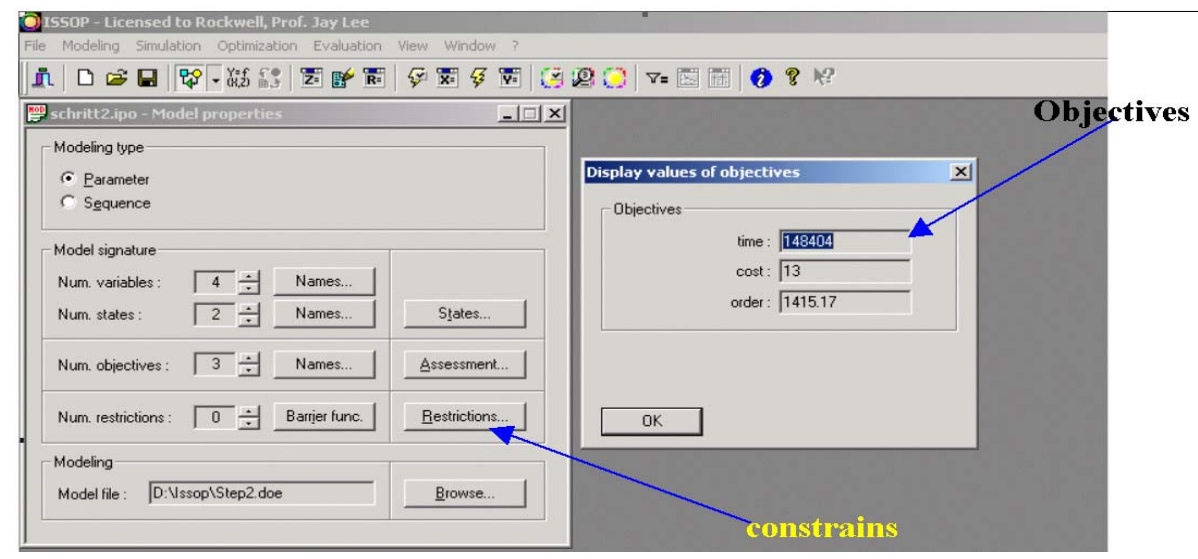

Figure 8: Initial objective value using Arena simulation

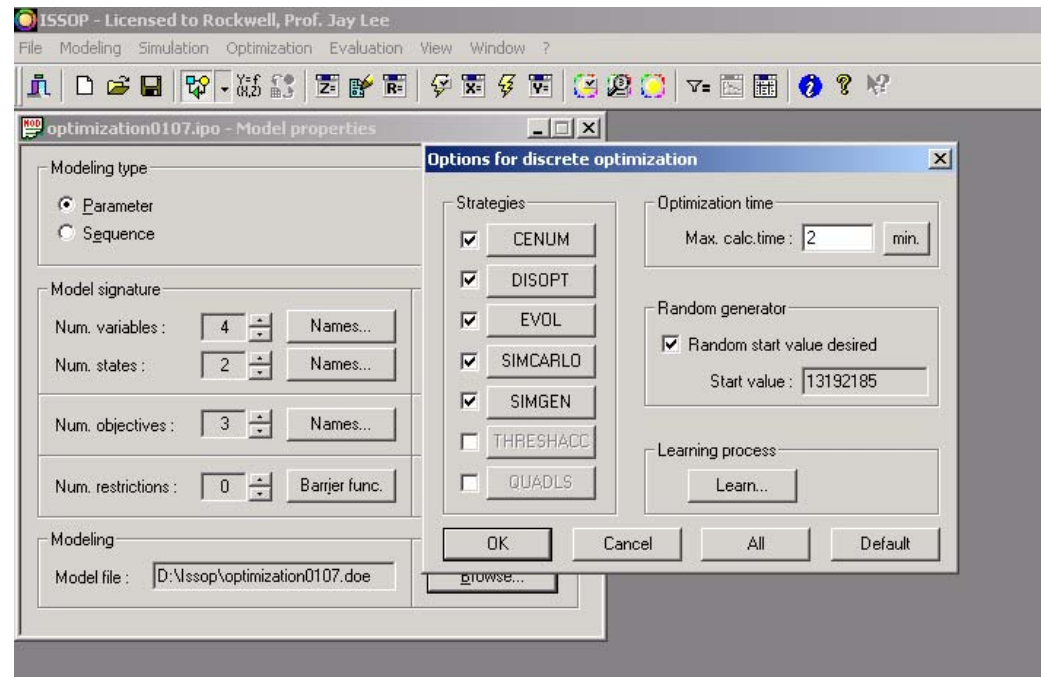

Figure 9: Optimization algorithms in ISSOP

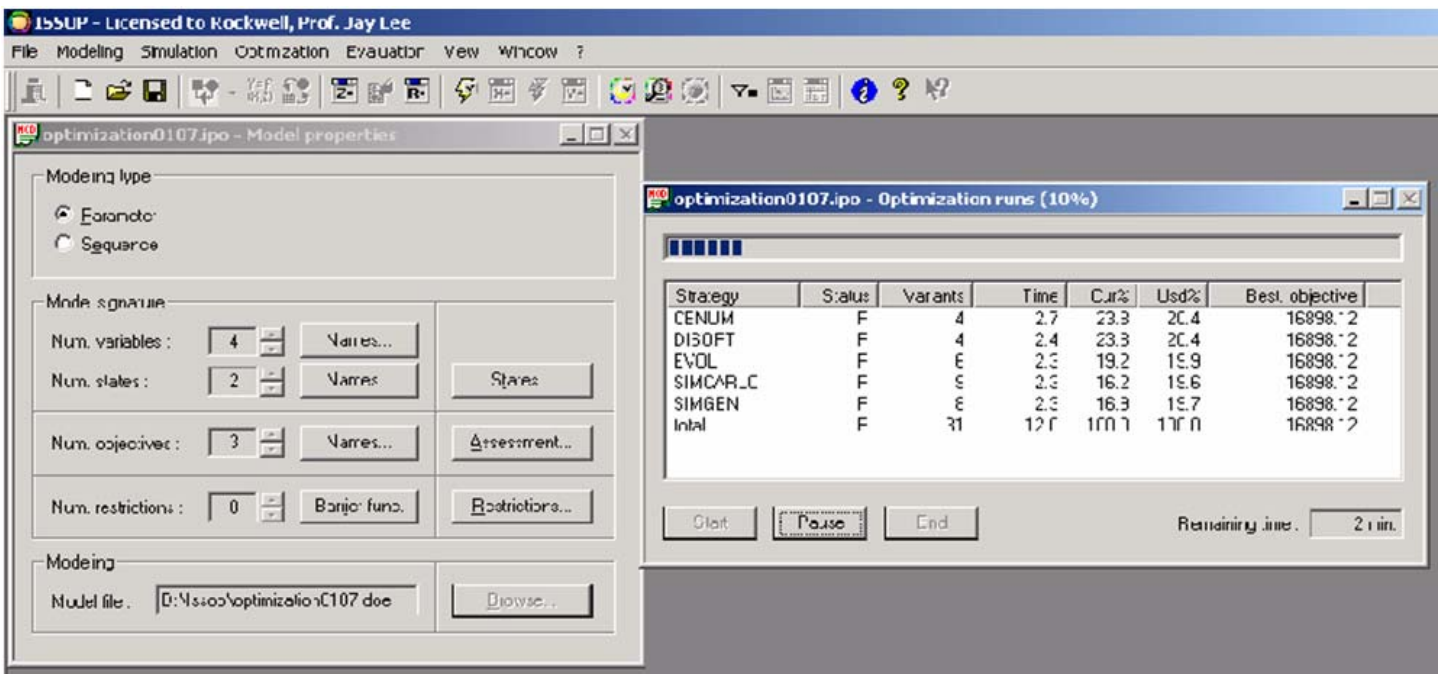

Figure 10: Optimal searching using several algorithms 


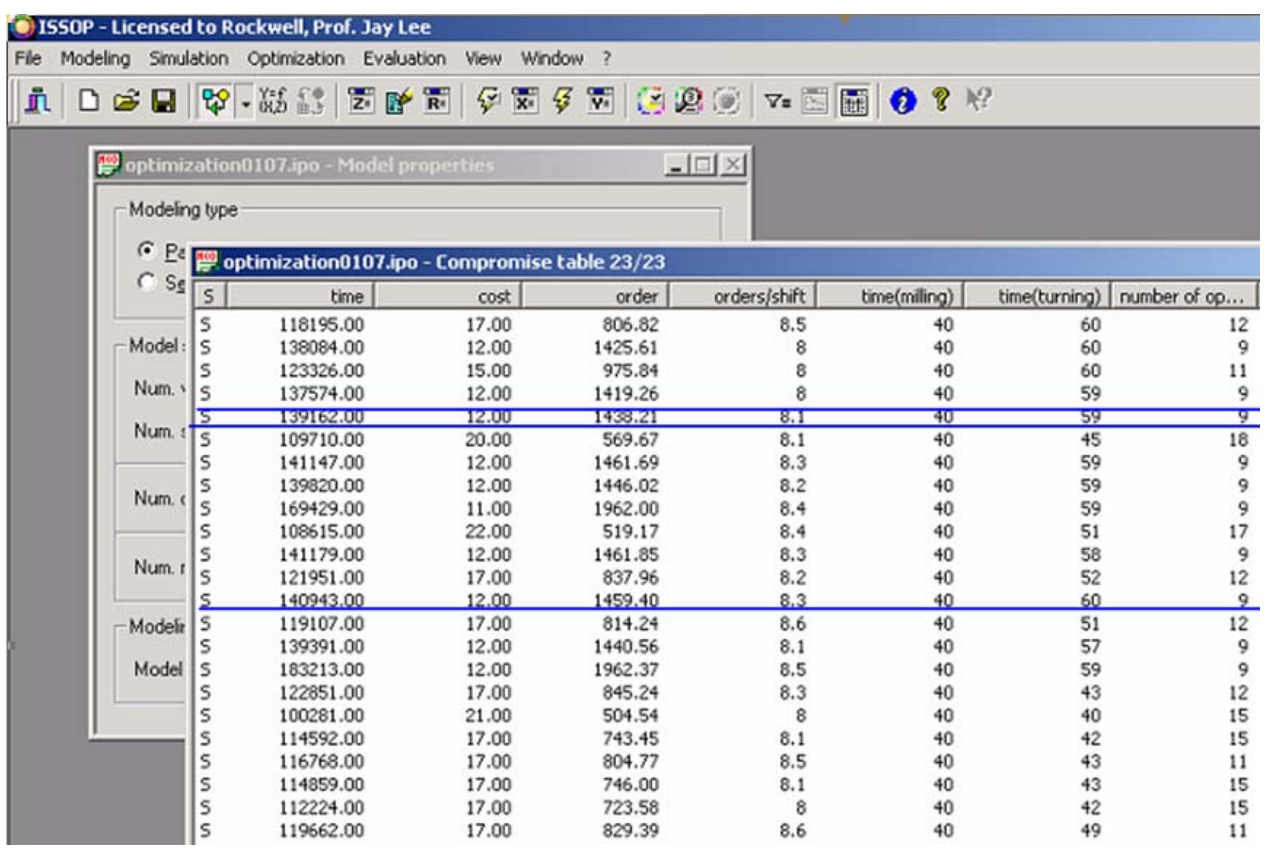

Figure 11: Optimal results

\section{CHANGING MAINTENANCE STRATEGY}

Based on the simulation performance and optimization, an optimal maintenance design is integrated with Intelligent Maintenance System (IMS) platform. Future IMS strategies will be modeled to make comparison between different policies. Analytical or precise simulated result on the system output variables will be identified including suggested downtime schedules and preventive maintenance crew size and stock investment. Close integration with machine level output with more accurate prediction will be addressed. The system will support high level decision and in response to e-business requirement of flexible maintenance. Figure 12 shows comparison between traditional and IMS platform for maintenance design.

\section{CONCLUSIONS}

This study used optimization software ISSOP and simulation software Arena for optimized maintenance design. It determines maintenance schemes and evaluates their effectives in respect of overall performance improvement. The system performance, measured in average throughput, is affected by multiple variables including station reliability, system layout, maintenance availability and maintenance policies. Based on the simulation and optimization of the manufacturing system, the optimal scenario is identified. Integrated simulation and optimization approach was validated through real-life testbed development. More mainte- nance policies could be used to explore for different aspects.

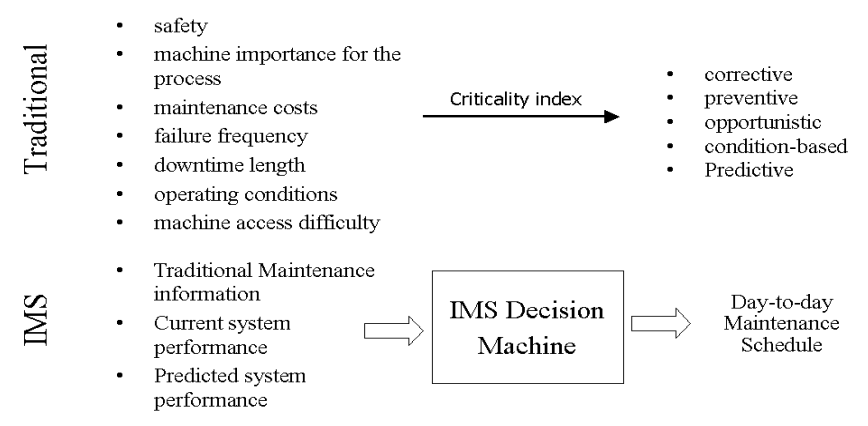

Figure 12: Comparison between traditional and IMS

\section{REFERENCES}

Andradóttir, S. 1998. A review of simulation optimization techniques. In Proceedings of the 1998 Winter Simulation Conference, ed. D. J. Medeiros, E. F. Watson, J. S. Carson, and M. S. Manivannan, 151-158. Piscataway, New Jersey: Institute of Electrical and Electronics Engineers, Inc.

April, J., F. Glover, J. Kelly, and M. Laguna. 2001. Simulation/ optimization using "real-world" applications. In Proceedings of the 2001Winter Simulation Conference, ed. B. A. Peters, J. S. Smith, D. J. Medeiros, and M. W. Rohrer, 134-138. Piscataway, New Jersey: Institute of Electrical and Electronics Engineers, Inc. 
Azadivar, F. 1999. Simulation optimization methodologies. In Proceedings of the 1999 Winter Simulation Conference, ed. B. A. Peters, J. S. Smith, D. J. Medeiros, and M. W. Rohrer, 93-100. Piscataway, New Jersey: Institute of Electrical and Electronics Engineers, Inc.

Beyer, J. 2006. Simulation-based optimization of supply chain inventory and forecast policy. In Proceeding Applied Simulation and Modelling. Rhodes, Greece.

Chen, S., M. Yang, and J. Lee. 2002. Optimization consideration of the intelligent maintenance system. In Proceeding of $5^{\text {th }}$ International Conference on Managing Innovative Manufacturing, Milwaukee, WI, USA.

Hani, Y., L. Amodeo, F. Yalaoui, and H. Chen. 2008. Simulation based optimization of a train maintenance facility. Journal of Intelligent Manufacturing 19(3):293-300.

Houshyar, A., A. Jafri, and V. Naiksatam. 2003. Comparison of different maintenance policies using simulation. In Proceedings of the IASTED International Conference on Modeling, Simulation and Optimization. 259265, Banff, Canada.

Intelligent Simulation and optimization system for manufacturing, organization and logistic. ARENA/ISSOP Handbook, 1997, Edited by SCS International San Diego, California, USA.

Krug, W. 1997. Intelligent simulations and optimization system for manufacturing, organization and logistic (ARENA/ISSOP). SCS-Europe.

Krug, W., Th. Wiedemann, J. Liebelt, and B. Baumbach. 2002. Simulation and optimization in manufacturing, organization and logistics. In Proceedings 14th European Simulation Symposium. ed. A. Verbraeck, W. Krug, SCS Europe BVBA.

Ólafsson, S. and J. Kim. 2002. Simulation optimization. In Proceedings of the 2002 Winter Simulation Conference, ed. E. Yücesan, C. H. Chen, J. L. Snowdon, and J. M. Charnes, 79-84. Piscataway, New Jersey: Institute of Electrical and Electronics Engineers, Inc.

Painter, M. K., M. Erraguntla, G. L. Hogg, Jr., and B. Beachkofski. 2006. Using simulation, data mining, and knowledge discovery techniques for optimized aircraft engine fleet management. In Proceedings of the 2006 Winter Simulation Conference, ed. L. F. Perrone, F. P. Wieland, J. Liu, B. G. Lawson, D. M. Nicol, and R. M. Fujimoto, 1253-1260. Piscataway, New Jersey: Institute of Electrical and Electronics Engineers, Inc.

Swisher, J. R., P. D. Hyden, S. H. Jacobson, and L. W. Schruben. 2000. A survey of simulation optimization techniques and procedures. In Proceedings of the 2000 Winter Simulation Conference, ed. J.A. Jones, R.R. Barton, K. Kang, and P.A. Fishwick, 119-128. Piscataway, New Jersey: Institute of Electrical and Electronics Engineers, Inc.
Yang, Z., Q. Chang, D. Djurdjanovic, J. Ni, and J. Lee. 2004. Maintenance priority assignment utilizing online production information. In Proceedings of 2004 JUSFA, 2004 Japan - USA Symposium on Flexible Automation, Denver, Colorado.

Yang, Z., Q. Chang, D. Djurdjanovic, J. Ni, and J. Lee. 2007. Maintenance priority assignment on-line production information. Journal of Manufacturing Science and Engineering 129(2):435-446.

\section{AUTHOR BIOGRAPHIES}

AHAD ALI is an Assistant Professor in the Department of Mechanical Engineering at the Lawrence Technological University. He received his B.S. in Mechanical Engineering from Bangladesh Institute of Technology, Khulna, M.S. in Systems and Engineering Management from Nanyang Technological University, Singapore and $\mathrm{PhD}$ in Industrial Engineering from University of Wisconsin - Milwaukee. Dr. Ali has published journal and conference papers. His research interests include manufacturing systems modeling, simulation and optimization, intelligent scheduling and planning, artificial intelligence, predictive maintenance, e-manufacturing, and lean manufacturing. He is member of IIE, INFORMS, SME and IEEE.

XIAOHUI CHEN is an Associate Professor of the Research Institution of Industrial Engineering at Chongqing University, as well as and the Deputy Director of the State Key Lab of Mechanical Transmission of China. She received her $\mathrm{PhD}$ in Manufacturing Systems Engineering from Chongqing University. Dr. Chen has published over 40 refereed journal articles, book chapters, and conference papers. Her research and teaching interests include system simulation (with emphasis in manufacturing environments) and maintenance systems and logistics engineering. He is a member of IIE and senior member of SMEC.

ZIMIN YANG is currently working in the Microsoft Shanghai, Advanced Technology Center in the area of software testing. He received a B.S. degree from Shanghai University of Science and Technology in 1997, an M.S. degree in Computer Science from the University of Michigan in 2005 and a Ph.D. degree in Mechanical Engineering in 2005, also from the University of Michigan. He worked at Shanghai General Motors from 1997 to 1999 as a maintenance engineer. His research interests include maintenance decision making, industrial simulation and optimization algorithms.

JUN NI is currently a Professor in the Department of Mechanical Engineering at the University of Michigan. He is the director of the S. M. Wu Manufacturing Research Center. He also serves as the Deputy Director of a NationalScience-Foundation-sponsored Engineering Research Cen- 
ter for Reconfigurable Machining Systems, and the codirector of a National-Science-Foundation-sponsored Industry/University Cooperative Research Center for Intelligent Maintenance Systems. His research and teaching interests are in the area of manufacturing science and engineering, with special focuses on precision machining, manufacturing process modeling and control, statistical quality design and improvement, micro/meso systems and manufacturing processes, and intelligent monitoring, maintenance and service systems.

JAY LEE is Ohio Eminent Scholar and L.W. Scott Alter Chair Professor at the University of Cincinnati and is founding director of National Science Foundation (NSF) Industry/University Cooperative Research Center (I/UCRC) on Intelligent Maintenance Systems (IMS) which is a multi-campus NSF Center of Excellence between the University of Cincinnati (lead institution), the University of Michigan, and the University of MissouriRolla. He received his B.S. degree from Taiwan, a M.S. in Mechanical Engineering from the University of WisconsinMadison, a M.S. in Industrial Management from the State University of New York at Stony Brook, and D.Sc. in Mechanical Engineering from the George Washington University. Dr. Lee has authored/co-authored over 100 technical publications, edited two books, contributed numerous book chapters, and hold three U.S. patents. His current research focuses on smart prognostics technologies for predictive maintenance, self-maintenance systems and innovative service business model studies. Currently, he serves as member of Board on Manufacturing and Engineering Design (BMAED) of National Research Council (NRC). Dr. Lee is also a Fellow of Society of Manufacturing Engineers (SME). 